\title{
Surgical repair of D-TGA with an aortopulmonary window and ventricular septal defects
}

\author{
Correção cirúrgica da transposição das grandes artérias com janela aortopulmonar e defeitos do septo \\ ventricular
}

\author{
Srikrishna M REDDY ${ }^{1}$, Akshay Kumar BISOI², Pranav SHARMA³, Sandeep CHAUHAN ${ }^{4}$
}

RBCCV 44205-1231

\begin{abstract}
D-Transposition of great arteries with an aortopulmonary window is a rare congenital anomaly. We describe a case of D-Transposition of great arteries with an aortopulmonary window and multiple ventricular septal defects in a 5-month boy who underwent successful surgical repair.
\end{abstract}

Descritores: Congenital heart defects/surgery. Transposition of great vessels. Transposition of great vessels/ surgery.

\section{INTRODUCTION}

D-Transposition of great arteries is commonly associated with other cardiac anomalies. However, association with an aortopulmonary window is rare and only very few cases have been reported in the literature [13]. We describe a case of D-Transposition of great arteries with an aortopulmonary window and multiple ventricular septal defects in a 5-month boy who underwent successful arterial switch operation and ventricular septal defects closure.

\section{CASE REPORT}

This study conforms to the principles outlined in the declaration of the Helsinki and was conducted after

1. MCh; Assistant Professor, Department of Cardiothoracic and Vascular Surgery, Jawaharlal Institute of Postgraduate Medical Education and Research, Puducherry - 605006, India.

2. MCh; Additional Professor, Department of Cardiothoracic and Vascular Surgery, All India Institute of Medical Sciences, New Delhi -110029, India.

3. MS; Senior Resident, Department of Cardiothoracic and Vascular Surgery, All India Institute of Medical Sciences, New Delhi 110029, India.

4. MD, PDCC; Professor, Department of Cardiac Anesthesia, All India Institute of Medical Sciences, New Delhi -110029, India.

\section{Resumo}

A transposição das grandes artérias com uma janela aortopulmonar é uma anomalia congênita rara. Descrevemos um caso de transposição das grandes artérias com janela aortopulmonar e múltiplos defeitos do septo ventricular em um menino de 5 meses submetido a tratamento cirúrgico com sucesso.

Descritores: Defeitos cardíacos congênitos/cirurgia. Transposição dos grandes vasos. Transposição dos grandes vasos/cirurgia.

obtaining approval from the Institutional Ethics Committee on Human Research and informed written consent from the parents.

A 5-month boy (weight, 3.5 kilogram) presented to our institute with complaints of failure to thrive, recurrent respiratory tract infections and progressively increasing cyanosis since birth. Oxygen saturation was recorded as $78 \%$ on room air. He was diagnosed on transthoracic crosssectional echocardiography to have D-Transposition of great arteries, an aortopulmonary window, patent arterial duct, multiple ventricular septal defects with severe pulmonary hypertension and normal left ventricular function. Patient did not undergo cardiac catheterization as the preoperative echocardiography was reliable in surgical decision making in terms of left ventricular mass, left ventricular posteriorwall thickness, left ventricular end-

Trabalho realizado no Department of Cardiothoracic and Vascular Surgery, Jawaharlal Institute of Postgraduate Medical Education and Research e no Department of Cardiothoracic and Vascular Surgery, All India Institute of Medical Sciences, New Delhi, India.

Endereço para correspondência: Dr Akshay Kumar Bisoi Additional Professor, Department of Cardiothoracic and Vascular Surgery. All India Institute of Medical Sciences - New Delhi, India -110029 E-mail: akshaykbisoi@gmail.com

Artigo recebido em 5 de julho de 2010 Artigo aprovado em 10 de outubro de 2010 
diastolic internal diameter and circular left ventricular configuration with the interventricular septum contracting in synergy with the left ventricular mass. Patient was planned for arterial switch operation, repair of aortopulmonary window and ventricular septal defects closure.

Intra-operatively (Figure 1) aorta was found to be anterior to the pulmonary artery with a large aortopulmonary window between them. The left coronary artery originated from sinus 1 and divided into the left circumflex and left anterior descending artery. The right coronary artery originated from sinus 2. It was difficult to develop an adequate sized button for each coronary separately as the two coronary orifices were close together in the posterior wall of the aorta. There was a large subpulmonary ventricular septal defect in addition to a small muscular ventricular septal defect.

Under cardiopulmonary bypass and moderate hypothermia, patent arterial duct was dissected, transfixed and divided, branch pulmonary arteries were snugged and occluded to avoid steal from systemic circulation and flooding of the pulmonary circulation through the aortopulmonary window. After clamping the aorta, with the pulmonary arteries still occluded, cold blood cardioplegia was given into the aortic root. ventricular septal defects were closed using expanded polytetrafluoroethylene patch through right atrial approach. The great arteries were dissected free and the aortopulmonary window was located. The great arteries were transected at the level of the aortopulmonary window (Figure 2A), which was included

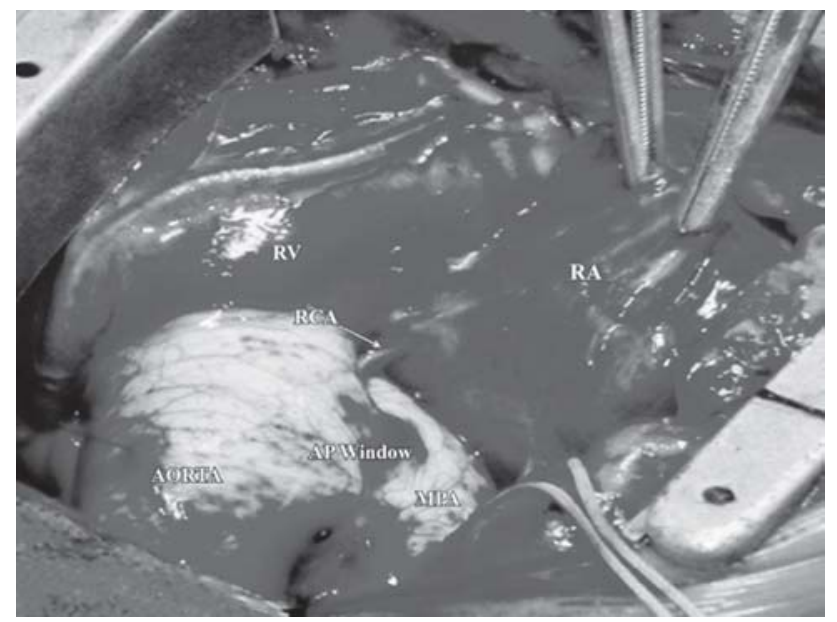

Fig. 1 - Intraoperative photograph showing D-Transposition of great arteries with an aortopulmonary window before surgical repair. Aorta was found to be anterior to the pulmonary artery with a large aortopulmonary window between them $R V$ - Right ventricle, $R A$ - Right atrium, MPA - Main pulmonary artery, RCA-Right coronary artery, AP Window - Aortopulmonary window in the line of transaction with care taken to avoid injury to the aortic and pulmonic valves. The commissure of the aortic valve between the coronaries was taken down, and both coronaries were mobilized on a single button in continuity with the window. The aortopulmonary window and the shelf with the coronaries were now included into the neo-aorta (Figure 2B and 2C). The defect in the neo-pulmonary artery was repaired using autologous glutaraldehyde fixed pericardium and the commissure was re-suspended. The Lecompte maneuver was performed and the great vessels were reconstructed (Figure 2D). The patient was weaned off bypass on minimal ionotropic support.

Post-operative course was uneventful except episodes of pulmonary hypertensive crisis in initial 72 hours following surgery that were managed successfully. Patient has been put on oral phenoxybenzamine, sildenafil, and captopril for six months. Follow-up echocardiogram at 18 months postoperatively showed good biventricular function with no regional wall motion abnormalities and unobstructed left and right ventricular outflow tracts.

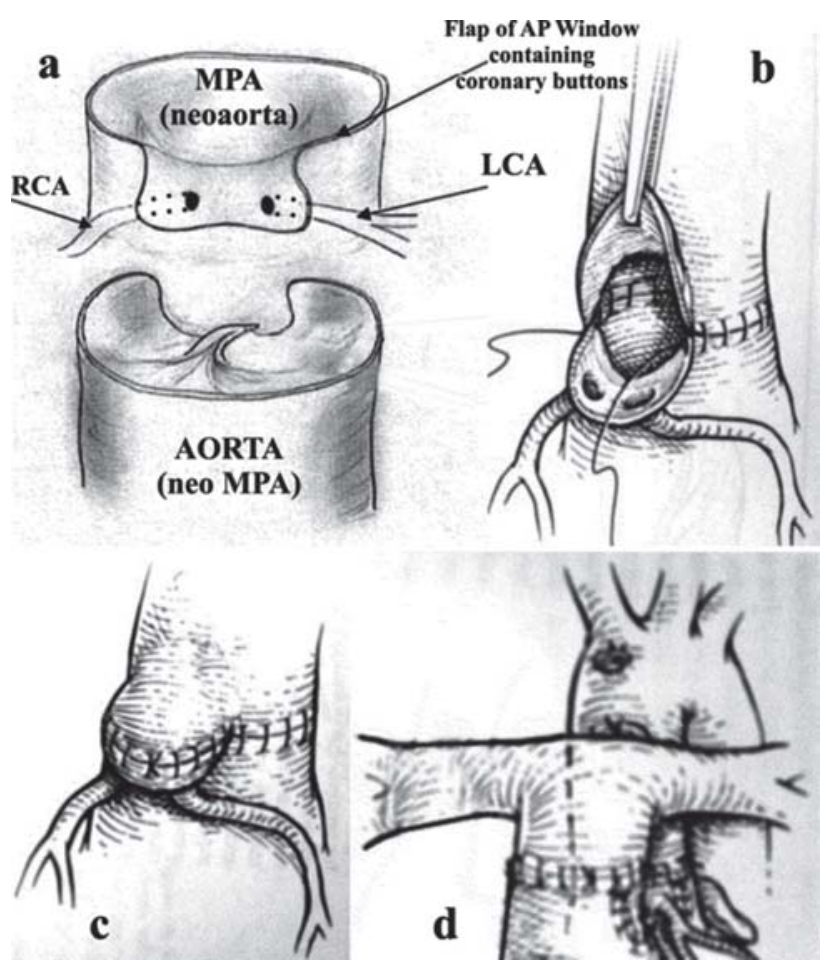

Fig. 2 - (a) Transection of great vessels at the level of aortopulmonary window with both the coronaries mobilized on a single button in continuity with the window. (b) and (c): Neo-aortic reconstruction by direct anastomosis of the shelf of aortopulmonary window containing the coronary button with the distal ascending aorta without using any patch. (d): Completed repair. RCA - Right coronary artery, LCA - Left coronary artery, MPA - Main pulmonary artery, AP Window - Aortopulmonary window 


\section{DISCUSSION}

D-Transposition of great arteries with an aortopulmonary window is a rare congenital anomaly and only very few cases have been reported in the literature [1-3]. Children with Transposition of great arteries presenting late in infancy often have regressed left ventricular mass. However, the presence of ventricular septal defect, patent arterial duct, significant aortopulmonary collaterals and an aortopulmonary window provide a pressure-head and prevent left ventricle from regression as seen in our patient [4].

Patients with isolated aortopulmonary window tend to have pulmonary vascular lesions at an early age. The early development of markedly abnormal changes in the pulmonary vascular bed of patients with D-Transposition of great arteries makes this combination of D-Transposition of great arteries with aortopulmonary window an extremely lethal one with high risk of pulmonary hypertensive crisis in the perioperative period as noticed in our patient [5].

Pulmonary hypertensive crises [6] are relatively common in high risk infants following surgery for congenital heart defects especially Complex Transposition as seen in our case, Truncus arteriosus, and Atrioventricular septal defects. Crises have an inherently "self-reinforcing" character to their development which mandates rapid and aggressive therapies. These episodes are potentially lethal but can be responsive to available treatment techniques. Prevention and early suppression of events are very important since once initiated, these episodes cluster. Specific monitoring is helpful and definitely indicated in high risk patients. But hyperoxygenation with manual hyperventilation, high dose analgesia and paralysis, correction of metabolic acidosis, hypoxia, hypercarbia, hypothermia, if any, use of intravenous infusion of nitriglycerine, phenoxybenzamine, or selective pulmonary vasodilators like Inhaled nitric oxide, Inhaled prostacyclin, IV prostaglandin E1, Adenosine, Endothelin antagonists (bosentan PO, tezosentan IV) are at present, the most frequently used and efficacious treatment modalities available.

Improved initial mortality rates and better long-term results have established arterial switch operation as the surgical procedure of choice for D-Transposition of great arteries. Associated structural pathology increases the complexity of and mortality associated with surgical repair; however, recognized structural contraindications are few, and the advantages of an anatomic repair are sufficiently great that arterial switch operation remains the method of repair for even complex D-Transposition of great arteries [7]. Although a conventional arterial switch operation can be safely performed in these patients, several technical modifications to redirect blood flow into the coronary arteries have been described $[1,8,9]$. Although the technique of coronary transfer making use of aortopulmonary window described in our case was similar to that described by Adluri et al. [9], we have not used any patch to create a pouch to contain coronary arteries and the neo-aortic reconstruction was done by direct anastomosis with ascending aorta without any torsion or excessive rotation of coronary button.

In conclusion, D-Transposition of great arteries with an aortopulmonary window is a distinct and a rare clinical entity that can be successfully repaired by arterial switch operation, but with high risk of pulmonary hypertensive crisis during perioperative period.

\section{REFERENCES}

1. Krishnan P, Airan B, Sambamurthy, Shrivastava S, Rajani M, Rao IM. Complete transposition of the great arteries with aortopulmonary window: surgical treatment and embryologic significance. J Thorac Cardiovasc Surg. 1991;101(4):749-51.

2. Marangi D, Peterson RJ, Ceithaml EL, Marvin WJ Jr. Surgical repair of d-transposition with aortopulmonary window: a case report. J Thorac Cardiovasc Surg. 1996;111(3):671-2.

3. Duca V, Sulliotti G, Maggio C, Corsello G. Transposition of the great arteries and aortopulmonary window in the same patient: clinical report and follow-up. Pediatr Cardiol. 2002;23(4):474-5.

4. Marwah A, Maheshwari S, Suresh PV, Misri A, Sharma R. Transposition of great arteries with aortopulmonary window: an unusual cause of prepared left ventricle at 11 months. Indian Heart J. 2005;57(4):353-4.

5. Kumar A, Taylor GP, Sandor GG, Patterson MW. Pulmonary vascular disease in neonates with transposition of the great arteries and intact ventricular septum. Br Heart J. 1993;69(5):442-5.

6. Wheller J, George BL, Mulder DG, Jarmakani JM. Diagnosis and management of postoperative pulmonary hypertensive crisis. Circulation. 1980;60(7):1640-4.

7. Van Praagh R, Jung WK. The arterial switch operation in transposition of the great arteries: anatomic indications and contraindications. Thorac Cardiovasc Surg. 1991;39(Suppl 2):138-50.

8. Takeuchi S, Katogi T. New technique for the arterial switch operation in difficult situations. Ann Thorac Surg. 1990;50(6):1000.

9. Adluri K, Barron DJ, Brawn WJ. D-transposition of the great arteries with an aortopulmonary window: a new corrective technique. Ann Thorac Surg. 2005;79(3):1066-7. 